\title{
Sovereignty, robustness, and short-term energy security levels. The Catalonia case study
}

\author{
Martí Rosas-Casals ${ }^{1}{ }^{*}$, Mariano Marzo ${ }^{2}$ and Pep Salas-Prat ${ }^{1,3}$ \\ ${ }^{1}$ Sustainability Measurement and Modelling Lab, Universitat Politècnica de Catalunya - Barcelona Tech, Barcelona, Spain \\ ${ }^{2}$ Geomodels Institute, Department of Stratigraphy, Paleontology and Marine Geosciences, University of Barcelona, Barcelona, Spain \\ ${ }^{3}$ SmartGrid.cat, Barcelona, Spain
}

Edited by:

Ugo Bardi, Università di Firenze, Italy

Reviewed by:

Enrico Sciubba, Sapienza University of Rome, Italy

Oscar Patrick René Van Vliet, ETH

Zürich, Switzerland

*Correspondence:

Martí Rosas-Casals, Sustainability

Measurement and Modelling Lab, Universitat Politècnica de

Catalunya - Barcelona Tech, 1 Colom

Street, Barcelona 08222, Spain

e-mail: rosas@mmt.upc.edu
Energy-related impacts and conflicts have been used to account for the emergence, maintenance, and collapse of complex societies. On the other hand in the last years, sustainability science has incorporated different frames of reference in order to facilitate the vision of sustainable futures. Most of them suggest that the search for satisfiers of human needs should be rooted on the local (a) construction of organic articulations of people with nature and technology and (b) generation of growing levels of social, economic, and energy selfreliance. This new regional kind of social agreement implies a redefinition of cultural norms and institutions, which at the same time leads toward increased levels of sovereignty for the social group engaged in this process. Sovereignty must not only be understood here in its political sense (as traditionally found in the literature) but also in its technological and energy acceptations. In this paper, we address this last constituent in terms of energy security levels and hierarchy in energy infrastructures between Spain and Catalonia, the latter being a Spanish autonomous community known for its sovereignty aspirations. We show a remarkable difference in energy security levels between both regions, which clearly hinders Catalonia's capacity to currently achieve a higher level of self-reliance in energetic terms. We suggest that this result is a consequence of the imperfect hierarchy that characterizes energy infrastructures at the spatial scale, and that it can be generalized to all regions where infrastructural systems have been historically assessed and developed under a nationwide planning scheme.

Keywords: energy security, critical infrastructures, legal framework, sovereignty, MOSES, social collapse, energy flows, robustness

\section{INTRODUCTION}

Energy is currently driving the global economy at all scales and nourishes the developmental capabilities of every nation and society: it is needed to power all kinds of machinery, to supply the industrial system with commodities, for the food production system, and to foster and sustain information and communication technologies (Bardi, 2013). At the same time, our energy system is absolutely dependent on fossil fuels, a fact that clearly jeopardizes our subsistence for, at least, three different reasons (MacKay, 2009): (a) fossil fuels are a limited resource, their availability will be reduced in the short-term due to an increased cost of extraction and they will probably run out in the mid-term; (b) our dependence on one energy source endangers our security of energy supply; and (c) global warming due to increasing carbon dioxide concentrations in the atmosphere from fossil-fuel burning is becoming the major threat to biodiversity and mankind as a result of climate change. How energy sources, flows, and transformation efficiencies affect the daily life of a social group, and its consequences in the technological and socioeconomic spheres in the near term is thus a fundamental issue in order to devise more sustainable futures.

In order to facilitate the vision of sustainable futures, sustainability science has been incorporating complementary frames of reference which, in one way or another, involve the definition of an overall human quality of life as a function of both the level of human needs met and the extent to which individuals or groups are satisfied with this level (Max-Neef et al., 1991; Costanza et al., 2008). Whereas human needs are constant, few, finite, and classifiable, the way these needs are satisfied change over time and between cultures according to the energy resource (and its thermodynamic limit) used by each civilization. Satisfiers and inputs required to fill each need must come from a social contract, involving different types of capitals (i.e., time, built, natural, social, or human) and based on (a) the generation of growing levels of self-reliance (constrained to available local energy resources) and (b) the construction of organic articulations of people with technology and nature.

Considering this new paradigm that sustainability science suggests, and given the fundamental role of energy in the definition of a living system, it seems energy and energy-related concepts could be used as a guiding principle for community-based social prospective activities. Here we use the term "prospective activity" as a proxy for any social enterprise involving political, cultural, or economic development of a group or region. If this prospective activity aims at a new (or transitional) definition of society under a human-scale developmental process, the social enterprise must 
involve a new definition of the system, and not a mere reproduction of what has been previously done. From the energy point of view, it means the achievement of a low carbon economy, based on renewable energies, and to regain control over energy use and exploitation, at an individual and community levels, through more energy efficient and demand side management activities, to name just a few (Odum and Odum, 2001). In post-industrial societies, current energy systems are the outcome of far-reaching, in time and space, historical processes, which involve many economic, cultural, and political decisions. Energy conversion and distribution infrastructures are basically the crystallized consequence of economic and political agreements, driven by economies of scale and constrained by the limitations of materials, energy, money, and information (Bettencourt et al., 2007). But in contrast with natural energy hierarchy, which accounts for fractal-like structures with spatial organization and material concentrations, and the increase of storage concentration with scale (Margalef, 1993; Odum, 2007), hierarchy in manmade energy systems is clearly broken at a specific level: infrastructures are obviously not fractal, storage levels cannot be indefinitely subdivided and, at a certain spatial scale, energy resources cannot be equally distributed. Thus, growing levels of self-reliance cannot be solely based on defining new political and social contracts but also on assessing how energy transmission and distribution infrastructures will finally fit into those new defined articulations.

In this paper, we use the IEA model of Short-term Energy Security (MOSES) (Jewell, 2011) to discuss and assess the plausibility of an energy sovereignty processes for the case study of Catalonia. We argue that attaining the maximum and sustainable energy self-reliance should be the focus goal of any new social contract that looks for a sustainable future. Current sovereignty-looking regions (i.e., Quebec, Scotland, Basque Country, Catalonia, etc.) should not base their discourse only in political decisions but firmly focused on how the inner dynamics of the social system will be strongly shaped by energy requirements and constraints. We end up highlighting some of the steps needed to develop a strong and durable energy policy framework in order to increase resilience and decrease risks at a regional level.

\section{MATERIALS AND METHODS}

The IEA MOSES can be used to analyze security of supply of seven primary energy sources (crude oil, natural gas, coal, bioenergy and waste, hydropower, geothermal energy, and nuclear power) and two groups of secondary fuels (oil products and biofuels) (Jewell, 2011). It considers four dimensions of energy security, which include external factors, related to imported energy, and domestic factors, related to use, conversion, and distribution of energy within national borders. External and domestic factors analyzed within the MOSES frame of reference reflect both risk exposure and resilience, defined here as the ability of energy systems to withstand disruptions. MOSES analyses the four dimensions of energy security using 35 indicators, chosen to signal the level of risk or adequacy of resilience for different energy sources and fuels in national energy systems. Each indicator relates to at least one of the four dimensions of energy security. Indicators are aggregated in two steps: (1) three bands of values (based on the observed ranges of the indicator values in IEA countries) corresponding to low, medium, and high vulnerability are established for each indicator; (2) this categorization is used to establish an energy security profile that takes into account how particular risks may exacerbate one another and how particular resilience capacities may mitigate specific risks. National energy systems can then be grouped in five energy security profiles, for each energy source or fuel, based on their overall risk exposure and resilience capacities. The energy security profiles are marked by letters (i.e., from A to E), moving from lower risk/higher resilience profiles (with highest energy security level labeled with A) to higher risk/lower resilience profiles (with lowest energy security level labeled with E). In this paper, we follow MOSES methodology to evaluate short-term energy security for two different regions: Spain and the autonomous region of Catalonia. Although analysis of power generation, electricity, and end-uses is still under development in MOSES, we have also included a very preliminary analysis of the electricity transmission infrastructure based on complex networks analysis (Solé et al., 2008).

At a national level, the Spanish energy system is currently characterized by a huge dependency on external and non-renewable energy sources (Danesin et al., 2012). In 2011, Spain imported $84.3 \%$ of its primary energy, well above the European average, worsening in 2012 by the largest coal imports, while only $15.7 \%$ of it was nationwide produced (Figure 1). The recent evolution of its commercial trade balance for oil and oil products and fuels reaches $40,000 \mathrm{M} €, 4 \%$ of its GDP, which is a severe burden for the current economic situation of the country (CORES, 2013). With an important amount of power generation derived from coal, net electricity exports decreasing and those of gasoline being practically constant, the Spanish energy system has reduced its energy efficiency in the last 2 years. Energy-related emissions of $\mathrm{CO}_{2}$ increased $2 \%$ in 2011 , mainly due to the increase on the share of coal and the lower contribution of hydropower to the electricity mix. Although high level of diversification providers of oil and natural gas mitigates much of the risk of this dependence in regard to security of supply, the energy sector, and therefore also the Spanish economy, remain exposed to significant price risk of these fuels.

As far as renewable energy is concerned, concentrated solar power and wind energy have substantially increased their share in energy generation during the last 5 years. Concentrated solar power almost doubled its capacity, which implies $70 \%$ of that installed worldwide. Wind represents roughly $20 \%$ of total power installed in Spain. It is equivalent to $9 \%$ of total wind power installed worldwide and $15.5 \%$ of average share in the Spanish electricity mix in 2011 (EDP Renovables, 2012). The use of biofuels has increased $18 \%$ compared to 2010 , following the projected path of integration into biodiesel consumption. As a whole, renewables reached $10.4 \%$ of primary energy conversion in Spain in 2011.

In terms of sectoral analysis and end-uses, transportation sector uses by far the most energy (25.6\%) and it accumulates the largest amount of $\mathrm{CO}_{2}$ emissions (28\%). In the case of Spain thus, this sector remains a priority in the design of sustainable policies. In terms of generated external value, Spain energy sector was reduced by two-thirds when external costs due to contamination by $\mathrm{CO}_{2}$, $\mathrm{SO}_{2}, \mathrm{NO}_{\mathrm{x}}$, etc., are discounted. Transport again is the sector, which generates the greatest amount of external costs, while electricity 


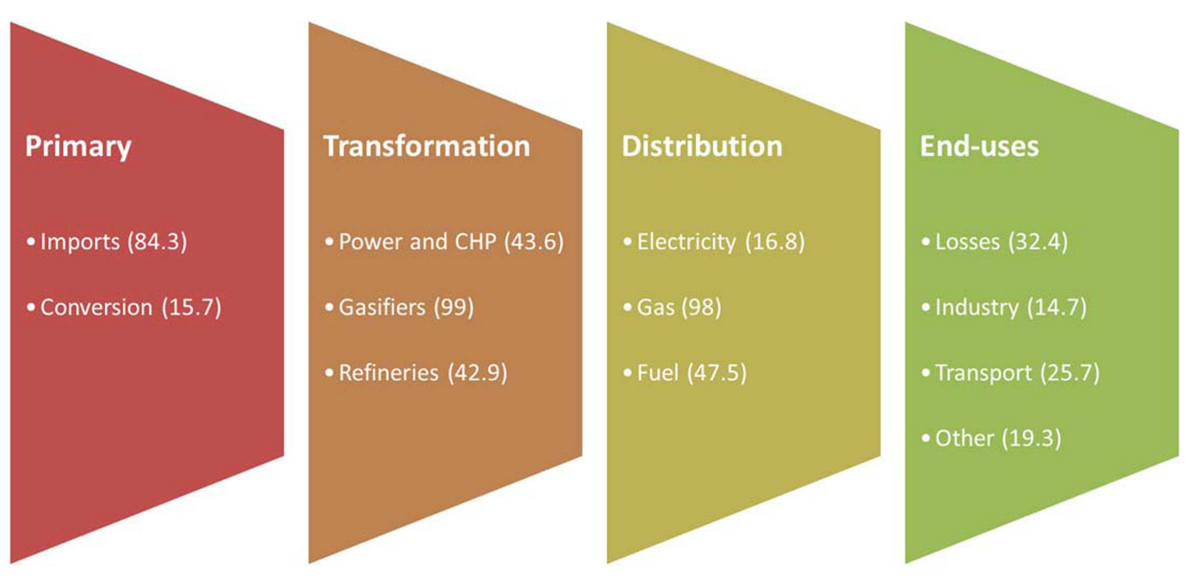

FIGURE 1 | Energy primary, transformation, distribution, and end-uses in Spain for year 2011 (values as percentage). Adapted from Danesin et al. (2012). Renewable energies are included in the conversion side.

generation sector is the best efficient one, mainly due to renewable energy inputs.

At the autonomous region level, the Catalan energy system is slightly different from the national one where it is embedded (Generalitat de Catalunya, 2012). Although Catalonia has also a high dependence on fossil fuels (meaning more than $75 \%$ of primary energy), it cannot rely on coal and it has much less renewable energy. The structure of primary energy that entered the system in 2009 was vastly dominated by oil (47.1\%), followed by gas $(24.6 \%)$ and nuclear energy (20.1\%), this last source being 55\% of the current electricity energy mix, in contrast to nuclear Spanish share, which is $<20 \%$ (Figure 2). The structure of final energy in 2009 was greatly dominated by oil (49.4\%), followed by electricity $(26.7 \%)$ and natural gas $(21.1 \%)$. This puts the Catalan economy in a delicate situation regarding what might happen to global level in terms of price and supply problems in oil, natural gas, and nuclear fuel. Almost $45 \%$ of petroleum products are intended for final consumption in the transportation sector, while $25 \%$ is allocated to non-energy uses, like its use as raw material in the petrochemical industry. Only $2 \%$ is used to generate electricity. As for natural gas, it is becoming a key component in the Catalan energy system: half of it is used to generate electricity, and the other half in the final consumption in industry, homes, and services. The current contribution of renewable energy is very small ( $<3 \%$ of total primary energy). This low percentage of contribution is very much below the Spanish average and the European Union, which is similar to the Spanish one. Last but not least, emissions of greenhouse gases in Catalonia have increased 60\% since 1990, well above the Kyoto protocol limits.

At the infrastructural level, two systems appear significant for MOSES analysis: crude oil and oil products on one hand, and natural gas on the other. These infrastructures are managed in centralized form. The Spanish oil and storage network (Figure 3) is managed by CLH Group ${ }^{1}$, one of the largest private companies in its sector at an international level, which comprises Compañía

\footnotetext{
${ }^{1}$ www.clh.es
}

Logística de Hidrocarburos and its subsidiary CLH Aviación. It has one of the largest oil product transportation and storage networks in the world, with over $4,000 \mathrm{~km}$ of oil pipeline and a storage capacity of 7.9 million cubic meters spread over 38 storage, 28 aviation facilities, and 8 refineries. In Catalonia, $C L H$ has four storage facilities in Barcelona, Girona, Lleida, and Tarragona (Figure 3B). The Barcelona and Tarragona facilities also permit the discharge of oil and oil products from tanker vessels. The oil pipeline network in this community is over $343 \mathrm{~km}$ long and connects all the facilities with one another, linking up with the rest of the oil pipeline network in the province of Lleida, to the west. In addition, this network has four oil pipeline and pumping facilities and is also connected to the refinery that operates in Tarragona, where we also find an important $C L H$ dispatching center. CLH Aviación, for its part, provides its aviation kerosene service into plane services at Girona and Barcelona airports in this autonomous region.

The Spanish gas system (Figure 4) is technically managed by $E N A G A S^{2}$. It has nearly $10,000 \mathrm{~km}$ of pipelines throughout the Spanish territory, three underground storage facilities located in Serrablo (Huesca), Gaviota (Vizcaya), and Yela (Guadalajara), and four regasification plants: Barcelona, Huelva, Cartagena, and Gijón. It also owns $40 \%$ of the Bilbao regasification plant. ENAGAS terminals in Spain have 2,646,500 $\mathrm{m}^{3}$ of liquefied natural gas storage capacity and an output capacity of $6,250,000 \mathrm{Nm}^{3} / \mathrm{h}$. In Catalonia, ENAGAS has one regasification plant in Barcelona, and two transmission and compression centers, in Tivissa and Banyeres, and one transmission center in Hostalric (Figure 4B). The gas pipeline in this community has two branches and it is over $450 \mathrm{~km}$ long.

Among energy infrastructures, power transmission networks stand as one of the most critical. Although power generation and end-uses of energy analysis will be reflected in subsequent versions of MOSES, transmission power network is presented here since we assess its vulnerability in the next section and include it in the final evaluation of energy security levels. Power transmission network 


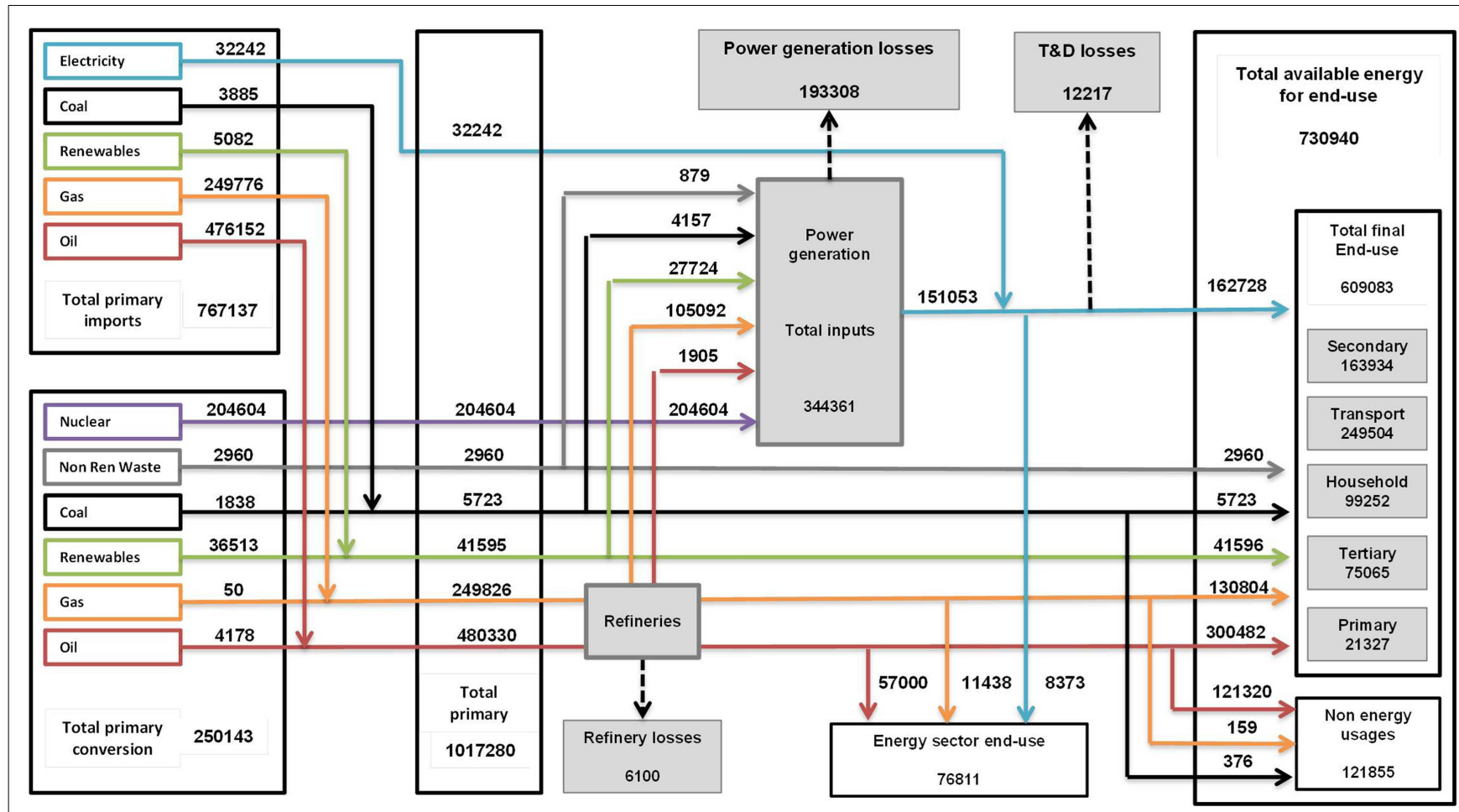

FIGURE 2 |The Catalan energy system in 2009. Values in terajoules. Adapted from Generalitat de Catalunya (2012).

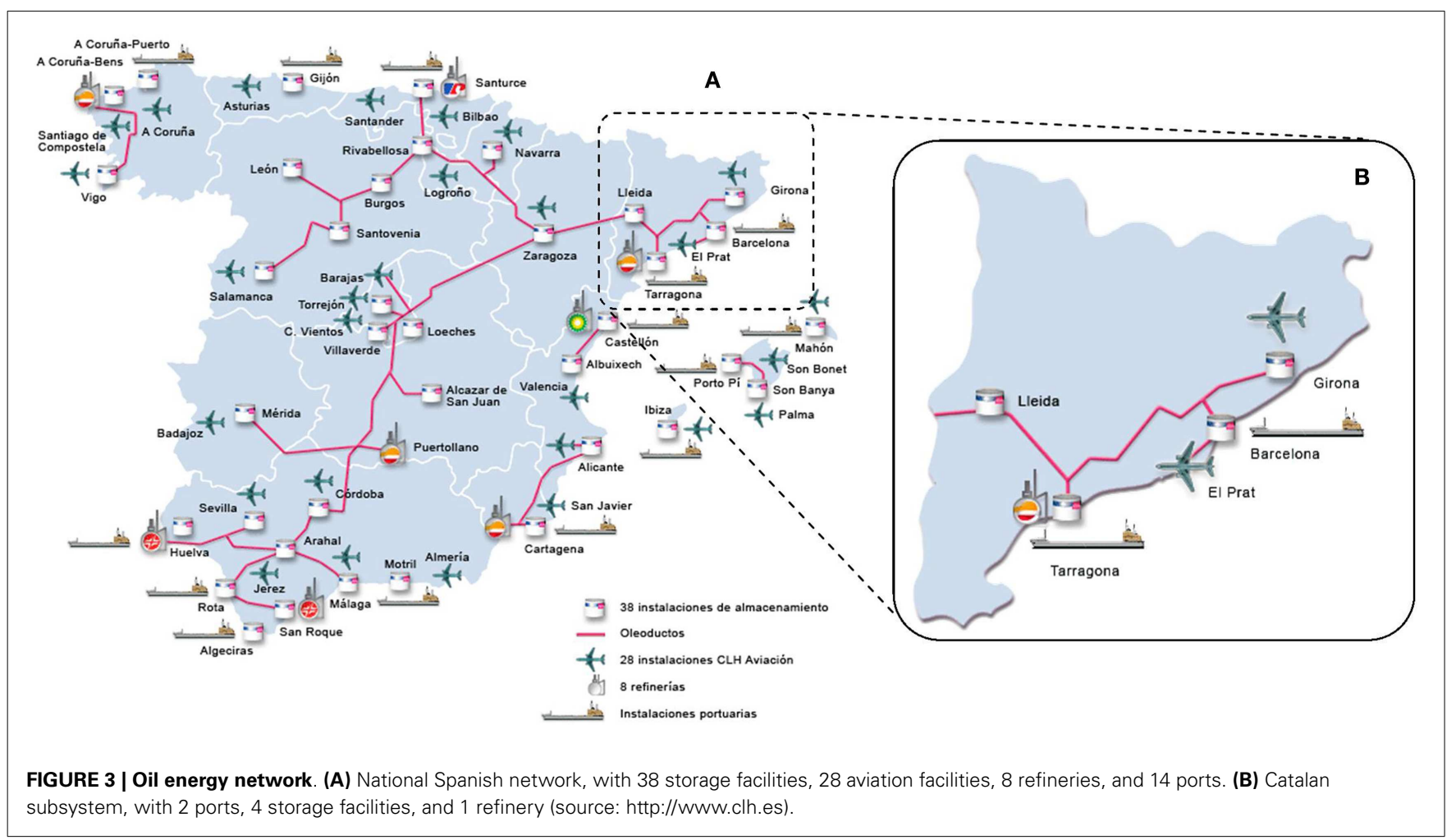




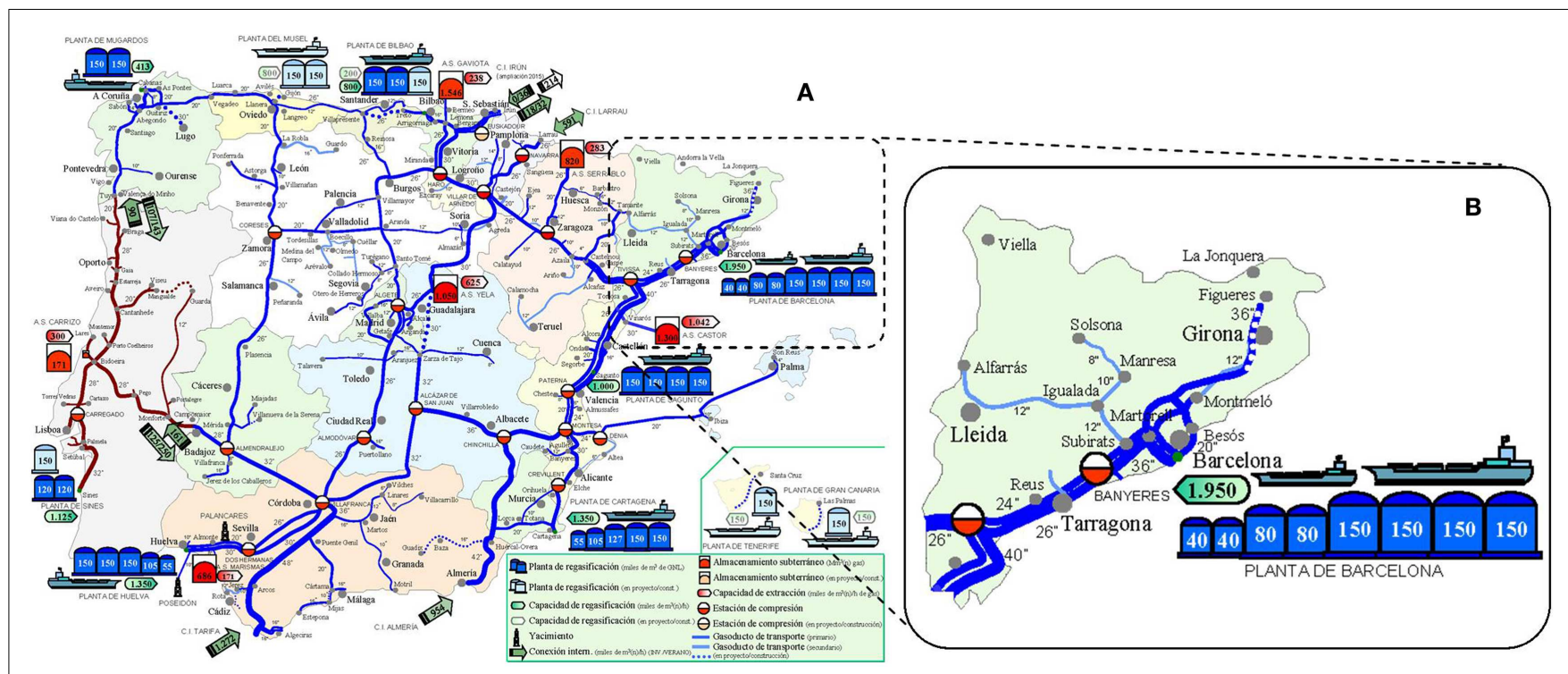

FIGURE 4 | Gas energy network. (A) National Spanish network, with 4 regasification plants, 45 transmission and compression centers, and 3 underground storage facilities. (B) Catalan subsystem, with one regasification plant and two compressor and transmission stations (source: http://www.enagas.es).

at the national level is managed by Red Eléctrica de España ${ }^{3}$. It works currently as the sole Transmission System Operator (TSO) of the Spanish electricity system. This transmission grid, considerably larger and bulkier in terms of lines and substations than its oil and gas counterparts, due to the energy-vector nature of electricity, is composed of more than $41,200 \mathrm{~km}$ of high voltage electricity lines and more than 5,000 substations, with some 78,000 MVA of transformer capacity (Figure 5). At the Catalan level, power transmission facilities include more than $9,000 \mathrm{~km}$ of high voltage electricity lines and more than 1,000 substations, with some 6,300 MVA of transformer capacity (Figure 5B). It is worth mentioning the strategic geographical situation of Catalonia, sharing borders with France, with respect to the European electric connectivity requirement among countries, which allows the accomplishment of the $10 \%$ electricity exchange level required by the EU between Spain and France (European Council, 2002).

\section{RESULTS}

Results are presented and analyzed following MOSES four-step methodology in a comparative way. These have been summarized in Table 1, where the evolution of energy security bands ("Security") at each step and for both regions, Spain (ES) and Catalonia (CAT), are shown as a consequence of existing constraints ("Constraint") at each step. Although some variability in indicators is observed, depending on the primary energy analyzed, two fundamental external risk indicators common to crude oil, oil products, and natural gas energy sources are net import dependence and political stability of suppliers. From this perspective, and since low risk from political stability of suppliers is strongly limited at the European level in general, and southern European regions in particular (more or less well-distributed amongst Africa, the Middle East, and

\footnotetext{
${ }^{3}$ www.ree.es
}

countries of the former Soviet Union), Step 1 makes a first segregation of regions with the former indicator as the most important. On the other hand, entry points (i.e., ports and pipelines) and diversity of suppliers are considered the cardinal external resilience factors and they are considered in Steps 2 and 3, respectively. Average storage levels, send-out capacity in the case of gas and other factors, are considered to evaluate the domestic resilience factor which, together with other complementary variables like volatility of domestic conversion, energy intensity, or number of refineries, helps MOSES to classify the regions with its final security level in Step 4. Although IEA has not provided us with the final classification of energy security levels for Spain, the following points review the evolution of the Spanish and Catalan security levels through these aforementioned steps and using the best available data known to the authors. The list includes one final and original security assessment related with the resilience of the electricity system in terms of complex networks.

- Crude oil: IEA countries have been segregated into three categories: low $(\leq 15 \%)$, medium $(40-65 \%)$, and high $(\geq 80 \%)$ import dependency. From this point of view, both, Spain and Catalonia, stand in the last group, a fact that gives a "B-E" security profile band. Spain has a high level of import infrastructures and diversity of suppliers (Jewell, 2011), but its storage levels are $<50$ days (IEA, 2011), which gives a final level security of C. The Catalan subsystem gives a more worrying situation, with a lower infrastructural capacity, similar diversity of suppliers but a storage capacity, which is roughly $10 \%$ of the Spanish one (4 storage facilities over 38, Figure 3 ). If we consider GDP as a proxy for energy use of a region and the fact that Catalonia shares approximately $18 \%$ of the Spanish GDP, this can gives us a rough estimate of half the storage levels of Spain for the Catalan region, and a final security level band of "C-D." 


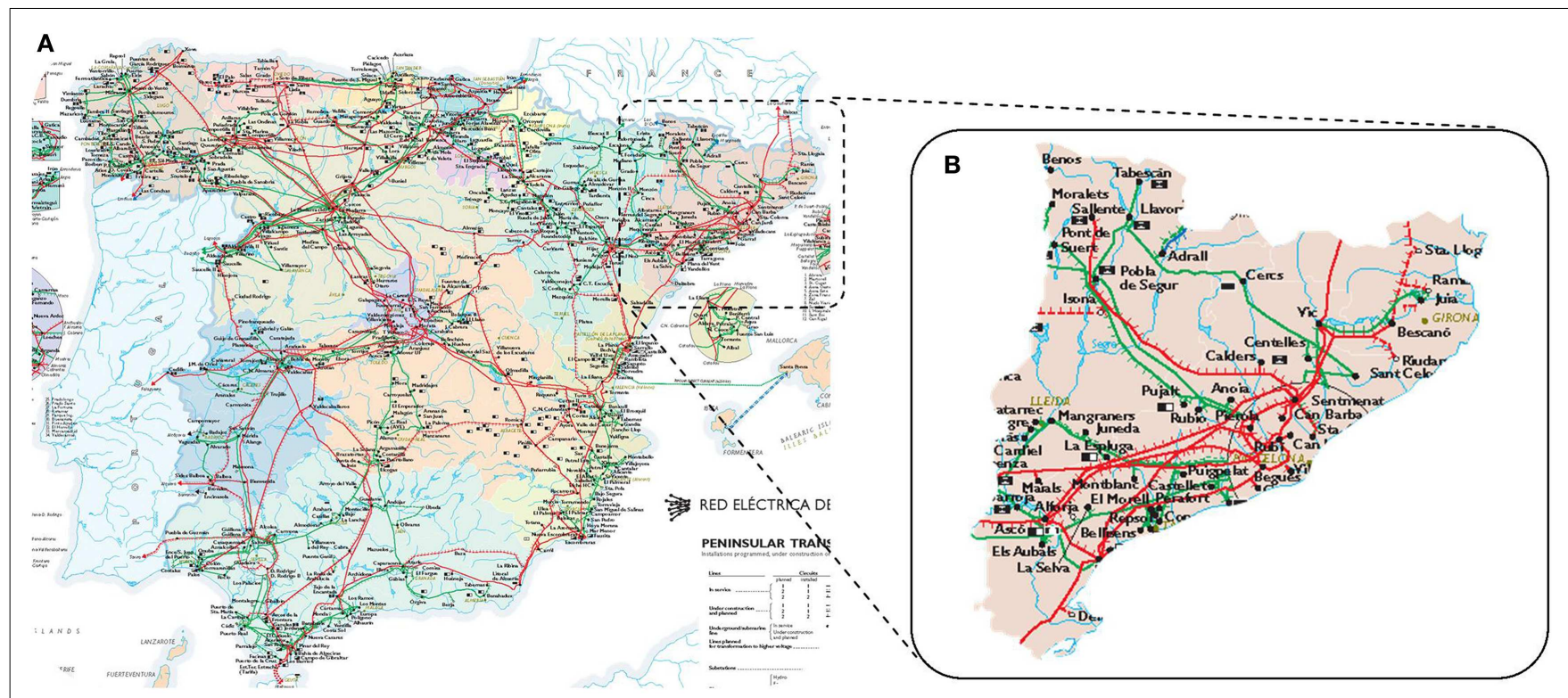

FIGURE 5 | Power transmission networks. (A) National Spanish network. (B) Catalan subsystem. Red and green colors show 400 and 220 kV electric lines, respectively (source: http://www.ree.es).

- Oil products: Oil products consumed can either be refined domestically or imported. MOSES segregates middle distillates from motor gasoline and other oil products, and the assessment process includes slightly more sophisticated substeps, which cannot be reproduced at lower level regional scale due to lack of available data.

- Natural gas: Assessing natural gas-related security levels follows a similar procedure as that described above for crude oil. In this case, IEA countries have been segregated into low $(\leq 10 \%)$, medium (30-40\%), and high ( $\geq 70 \%)$ import dependency. From this point of view, both regions stand in the last group, a fact that gives a "B-E" security profile band. Spain has a high level of import infrastructures and diversity of suppliers, and high levels of send-out capacity (Jewell, 2011), which gives a final "B" security level for the country. On the contrary, the Catalan subsystem gives a more unfavorable situation, with an infrastructural capacity so diminished that cannot be counterbalanced by other more favorable factors. Since its send-out capacity is not available, Catalonia has a final " $D-E$ " band of security levels.

- Coal: Security of coal supply is analyzed by considering total coal flow and import dependency and proportion of underground mining as external and domestic risks, respectively. Entry points and diversity of suppliers are used as indicators of external resilience. Spain imports $55 \%$ of its coal and $47 \%$ of its internal conversion is from above-ground mining ${ }^{4}$, which gives an " $\mathrm{A}$ " energy security level to the country. Catalonia imports $68 \%$ of its coal (Figure 2) and although supplier diversity could be considered high, having only two sea ports as import infrastructures imply a final security level band of "D-E."

${ }^{4} \mathrm{http} / / / \mathrm{www} \cdot \operatorname{lne} . e s /$ cuencas/2012/11/04/mitad-carbon-extraido-espana-procedeminas-cielo-abierto/1321532.html
- Biomass, biofuels, and waste: As in the case of oil products, the assessment process includes slightly more sophisticated substeps, which cannot be reproduced at lower regional level due to lack of available data.

- Nuclear power: MOSES assesses the likelihood of disruption in the supply of electricity produced from nuclear power plants but it does not assess the safety of nuclear power plants. This likelihood depends on domestic risks (i.e., unplanned outage rate and average age of nuclear power plants) and domestic resilience factors (i.e., diversity of reactor models and number of nuclear power plants). With six nuclear power plants built essentially in the $1980 \mathrm{~s}^{5}$, Spain is in the low security level range, with an unplanned outage rate between 3 and $6 \%$ (defined and reported by the Atomic Energy Agency) and a number of power plants between 4 and 10, which gives a final security level of "D." For its part, assuming the same level of outage rate, Catalonia has in its region only three nuclear facilities, which gives a final security level of "D-E" to the region.

- Renewables (geothermal, hydropower, solar, wind, and ocean energy): These are primarily used to produce electricity, so the security of their supply would be roughly related to the vulnerability of electricity system. Although MOSES provides a quantitative evaluation of hydropower in particular in terms of its conversion volatility, we cannot give an accurate estimation of the Spanish nor the Catalan hydropower conversion volatility due to lack of available data.

- Power network: Reliable penetration (and consequent high security) of variable renewable and non-renewable power sources depends on the flexibility of the whole electric system where

\footnotetext{
${ }^{5} \mathrm{http}: / /$ www.csn.es/index.php?option=com_content\&view=article\&id= 25\&Itemid $=18 \&$ lang $=$ es
} 
they are embedded (Chandler, 2011). This flexibility depends on technological, geographical, institutional, and market factors and its systematic assessment presents a remarkable level of complexity. Rather, here we present a simplified assessment process of the power network structural security based on complex networks science (Newman, 2010). The method has been shown useful in order to segregate European power transmission networks into fragile and robust ones, revealing meaningful correlations with real malfunction events (Solé et al., 2008). It can be summarized as follows (details can be found in the Supplementary Material of this article): (a) a probability distribution of a specific topological variable (in this case the so-called degree, defined as the number of cable lines connected to each substation) is chosen in order to characterize each network; (b) a theoretical prediction of the critical fraction of substations needed to disconnect the network, based on random and selective removal of substations, is combined with experimental evidence; and (c) the deviation obtained from the theoretical prediction is used as the final performance of the network in terms of the vulnerability of the electricity system. In the case of Spain (Figure 5A), positive deviations from theoretical prediction are less than $5.5 \%$, whereas negative deviations for Catalonia reach $13.6 \%$ thus signaling a less robust network for the latter (Figure 5B). Since the Spanish network was originally classified in the fragile group (Solé et al., 2008), we have given this network a "C" energy security level and a final " $D$ " security level for the Catalan one.

\section{DISCUSSION}

Energy security concepts have been historically shaped by separate policy challenges and academic disciplines (Cherp and Jewell, 2011; Jewell and Cherp, 2013). The energy security conceptual core is rooted on sovereignty and geopolitics, and it focuses on risks arising from foreign control over crucial energy systems. In the last several decades, two complementary perspectives have also been considered in order to deal with the increasing meta-complexities and uncertainties that characterize energy systems nowadays. On the one hand, the "robustness" perspective, more connected with computer analysis, modeling, and engineering of complex and critical infrastructural systems. On the other, the "resilience" perspective, related with the economic analysis of energy markets and with views of energy as a commodity rather than a public good. Although MOSES seeks to integrate the three perspectives, it predominantly focuses on sovereignty and robustness concerns. It also excludes relevant medium- and long-term perspectives on energy security, such as the environmental impact of energy systems, rapidly growing demand for energy services, level and volatility of energy prices, and the depletion of natural resources. It deals exclusively with national indicators and does not handle security of solar, wind, and ocean energy, which cannot be analyzed separately from security of electricity systems. That being recalled, results shown in Table 1 highlight the vulnerabilities of both the Spanish and Catalan energy systems, using MOSES as it is currently defined. As we can see, final classification levels of energy security for Catalonia are always equal or lower than those found for Spain, suggesting a strong and significant energy hierarchy disruption between both regions. Among all primary energy sources, natural gas and coal offer the most disparate levels of security between both regions: B to D-E and A to D-E, for Spain and Catalonia, respectively. On the contrary, security levels for crude oil, nuclear, and the power network are much more similar and in the lower range, suggesting similar security issues for both regions. This generalized reduction of security levels for Catalonia comes as an expected result, since MOSES does not consider normalized indicators. In fact, if a region has only a single pipeline and only imports from a single source, being exposed to high risk or having a low-resilience capacity is not mitigated by having a small energy system: in this case, whether a country is small or large is irrelevant to its high external vulnerability. In this sense, and since historically economies of scale have been the most important driver for energy infrastructures, these results could be generalized to regions embedded in other regions: these will generally have an equal or lower energy security level than its embedding region. The validity of MOSES in the limit of the lowest spatial scale (e.g., the definition of a region such as a metropolitan area) remains unclear and it obviously imposes a constraint on its applicability. Divergence between security levels will depend also on how long both regions have been historically coexisting and the centralization level of energy-related decision processes. It is important to recall that no single set of metrics is suitable for assessing energy security for all purposes in all situations and that the identification of energy security profiles must come from empirical groupings and implicit judgments on what is an adequate level to consider an indicator a signal of sufficiently high-risk or low-resilience to influence the energy security risk profiles (Jewell and Cherp, 2013).

The security of an energy system is not limited to the state of its infrastructure (the primary focus of MOSES), but also to the effectiveness of its policies and regulations as well as the market structure and the investment climate. In order to define a more secure energy model at a regional level, and for Catalonia in particular, generic responses based on human scale development, which conciliate environmental, social, and economic demands, must consider lower energy intensity, diversity of energy options, and research and development of new energy carriers (Cherp and Jewell, 2011). In order to minimize risk, specific responses play an important role for the Catalan case study and for each of the three perspectives mentioned above: sovereignty, robustness, and resilience (Table 2). The most important one is the definition of a strong, durable, and secure legal framework (currently non-existing neither in Spain nor in Catalonia), that at the same time facilitates short, medium, and long term energy planning. A more secure regional energy model should be based on the current European legislative frame. This is: (1) the "Third Energy Package" (European Parliament and Council, July 2009) on the opening of internal gas and electricity markets, which highlights the importance of separation of activities in energy markets to prevent vertical integration leading to monopolistic practices, and in total alignment with the objectives of the "European Strategy 2020 " to achieve a secure, competitive, and sustainable energy supply system for the European Union; (2) the Directive 2004/8/EC of the European Parliament and of the Council (European Union, 2004) on the promotion of cogeneration based on the useful heat demand, to promote small power installations; (3) the Directive 2009/28/EC (European Union, 2009) on the promotion of the use of energy from renewable sources, which establishes the obligation 
Table 1 | Energy security levels for different primary energy sources in Spain (ES) and Catalonia (CAT), including power network infrastructure, a security level not considered in MOSES procedure.

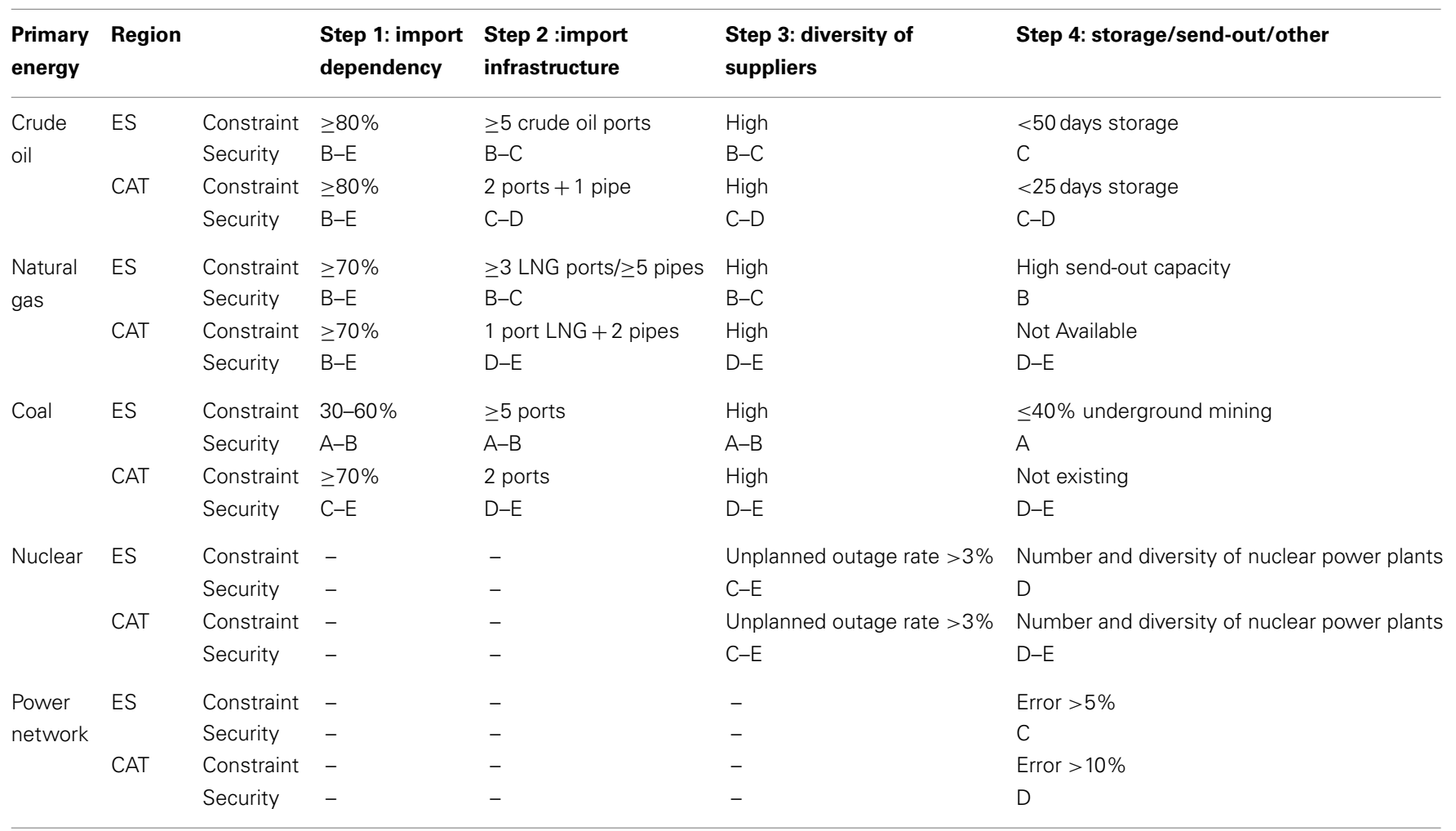

Table 2 | Perspectives on energy security and options to improve sovereignty, robustness, and resilience for the Catalan case study [adapted from Figure 1 (Cherp and Jewell, 2011)].

\begin{tabular}{|c|c|c|c|}
\hline Perspective & Threats & Risk minimization & Specific responses \\
\hline Sovereignty & $\begin{array}{l}\text { Sabotage and terrorist attacks; political; } \\
\text { embargoes; malevolent exercise of } \\
\text { market power }\end{array}$ & $\begin{array}{l}\text { Protection of infrastructures; } \\
\text { political/economic control of energy } \\
\text { systems; trusted suppliers; } \\
\text { switching to domestic fuels }\end{array}$ & $\begin{array}{l}\text { Medium and short-term energy planning; legal } \\
\text { security; biomass }\end{array}$ \\
\hline Robustness & $\begin{array}{l}\text { Failures of energy infrastructure; } \\
\text { extreme natural events; demand on } \\
\text { outgrowing supply; resource depletion }\end{array}$ & $\begin{array}{l}\text { Upgrading/renewal of } \\
\text { infrastructures; adoption of safer } \\
\text { technologies; switching to more } \\
\text { abundant resources }\end{array}$ & $\begin{array}{l}\text { Smart-grid development; distributed and on site } \\
\text { power generation; renewable energy; energy } \\
\text { efficiency; biomass, wind and solar }\end{array}$ \\
\hline Resilience & $\begin{array}{l}\text { Technology changes; variations of } \\
\text { climate; market; volatility; regulatory } \\
\text { changes }\end{array}$ & $\begin{array}{l}\text { Adoption of new technologies; } \\
\text { climate change adaption and } \\
\text { mitigations policies }\end{array}$ & $\begin{array}{l}\text { Medium and short-term energy planning; long } \\
\text { term energy planning; transparent pricing } \\
\text { system and electricity bill; legal security }\end{array}$ \\
\hline
\end{tabular}

to rationalize and to accelerate the administrative procedures to authorize the distribution and transport network connections; (4) the 2012/27/UE Directive (European Union, 2012) on energy efficiency, which considers the contribution of distributed generation to reduce load off peak hours, the connection with sources close to the place of use, and distributed storage as some of the mechanisms important to improve the energy efficiency of the electrical system. It also proposes economic schemes (as "dynamic tariffs") to encourage distributed generation as an effective way of demand response; and (5) the legislative package on climate and energy, specified within the 20-20-20 objectives (reduction of $\mathrm{CO}_{2}$ emissions, the introduction of renewable energy, and reducing consumption) and establishing a firm commitment to a low carbon and green economy. Secondly, electricity distribution networks should act as the basic infrastructure that enables the renewable penetration across the region. Information and communication infrastructures, such as optical fiber, have to be deployed along with power networks to reach equitable economic 
and social development and same opportunities among cities and rural areas. Within this process, smart metering roll-out is one of the short-term commitments that must be deployed as a basis of the future power network. To do this optimally, some technical issues (such as standards) and non-technical ones (such as business models related to smart meters, open data, and privacy, among others) need to be addressed. The confluence of telecommunications and power infrastructures (for instance with a public-private partnership that plays as a neutral operators) should be explored to adapt to the multi-utility approach for rural and semi-rural areas and to avoid dominant positions in the market. Last but not least, a thorough evaluation of the particularities of the Catalan renewable energy potential and its relation with the economic sphere must be conducted, including the assessment of wind (more than $3000 \mathrm{MW}$ potential in an environment compatible areas), photovoltaic (huge potential under net metering schemes and solar farms), and concentrated solar power (Generalitat de Catalunya, 2012).

In the approximation presented here, four strong simplifications have been made regarding the complex networks approach to power transmission grid reliability (Watts and Strogatz, 1998): (1) all transmission lines are assumed to be bidirectional and hence the resulting graph is undirected; (2) the nodes of the network (i.e., generators, transformers, substations, and so on) are treated as identical, featureless vertices; (3) all transmission lines are assumed to be identical (that is, unweighted, with no attributes associated to edges) ignoring the important fact that voltages vary and that different lines have significantly different carrying capacities, impedances, and physical constraints; and (4) only the transmission network is considered, thus ignoring an entire (and much larger) associated network, responsible for distributing power from the grid to individual house, offices, factories, etc. Despite these oversimplifications, this model has been shown to be suitable for the analysis of the robustness of transmission networks (Solé et al., 2008). Nonetheless, energy security in terms of power grids at regional and local levels must also include distribution networks in order to take into account some of their very particular features, like renewable energy injections and voltage stability. In the authors' view, the development and validation of such an evolved model (to the author's knowledge, non-existent yet) capable of translating these features in terms of security and reliability of the power grid, would significantly complete and improve the MOSES methodology.

\section{CONCLUSION}

This paper presents an application of the IEA MOSES to evaluate security of supply of individual sources and fuels in Spain and Catalonia. Results show an important difference in energy security levels between these regions, suggesting a strong hierarchical break between them at the energy systems level. Our results imply a remarkable deficit in terms of energy security levels for Catalonia if it was involved in a sovereignty scenario in the near term. In order to define a more secure energy model at a regional level, less risky and more resilient, the evolution toward a new energetic paradigm should be enclosed in a strong and durable legal framework, which promotes (a) the opening of internal energy markets (which highlights the importance of separation of activities to prevent vertical integration leading to monopolistic practices), (b) the promotion of cogeneration based on useful heat demand (to promote small power installations), (c) the promotion of renewable sources (which establishes the obligation to rationalize and to accelerate the administrative procedures to authorize the distribution and transport network connections), and (d) energy efficiency (which considers the contribution of distributed generation to reduce load off peak hours, the connection with sources close to the place of use, and distributed storage). Although the adoption of policies aimed at deploying any of this aforementioned aspects is fundamental in order to decrease external and domestic risks and increase resilience in energy security, an overall framework based on human scale development and quality of life is needed in order to redefine human needs and how these needs can be finally satisfied in terms of energy.

\section{ACKNOWLEDGMENTS}

We thank J. Jewell for her invaluable comments and clarifications regarding energy security issues in general and MOSES methodology in particular. We thank Oscar Patrick René Van Vliet for his efforts and comments, which have remarkably improved the manuscript. Martí Rosas-Casals thanks S. Delgado-Raack for most fruitful conversations and help in defining the structure of this paper and its contents. He wishes also to thank specially A. Beckett and J. Miller for inspiring conversations and attitudes toward energy-related problems and policies.

\section{SUPPLEMENTARY MATERIAL}

The Supplementary Material for this article can be found online at http://www.frontiersin.org/Journal/10.3389/fenrg.2014.00016/ abstract

\section{REFERENCES}

Bardi, U. (2013). The grand challenge of the energy transition. Front. Energy Res. 1:2. doi:10.3389/fenrg.2013.00002

Bettencourt, L. M. A., Lobo, J., Helbing, D., Kühnert, C., and West, G. B. (2007). Growth, innovation, scaling, and the pace of life in cities. Proc. Natl. Acad. Sci. U.S.A. 104, 7301-7306. doi:10.1073/pnas.0610172104

Chandler, H. (2011). Harnessing Variable Renewables. A Guide to the Balancing Challenge. Paris: IEA.

Cherp, A., and Jewell, J. (2011). The three perspectives on energy security: intellectual history, disciplinary roots and the potential for integration. Curr. Opin. Environ. Sustain. 3, 202-212. doi:10.1016/j.cosust.2011.07.001

CORES. (2013). Boletín Estadístico de Hidrocarburos 2012. Madrid. Available at: http://www.cores.es/sites/default/files/archivos/publicaciones/informeest-2012-julio-2013.pdf

Costanza, R., Fisher, B., Ali, S., Beer, C., Bond, L., Boumans, R., et al. (2008). An integrative approach to quality of life measurement, research, and policy. S.A.P.I.EN.S $1,17-21$.

Danesin, A., Lascorz, M. C., Linares, P., López-Peña, Á, Pérez-Arriaga, I., and Rodrigues, R. (2012). Informe Sobre Energía y Sostenibilidad en España 2012. Madrid. Available at: http://web.upcomillas.es/Centros/bp/Documentos/ Actividades/Observatorio/Marzo2013/Informe_Observatorio2012_web.pdf

EDP Renovables. (2012). Impacto Macroeconómico del Sector Eólico en España. Madrid. Available at: http://www.aeeolica.org/uploads/documents/Estudio_ macro_AEE_2012.pdf

European Council. (2002). Communication from the Commission to the Spring European Council in Barcelona: "The Lisbon Strategy-Making Change Happen" (Synthesis Report). Available at: http://www.consilium.europa.eu/uedocs/cms_data/ docs/pressdata/en/ec/71025.pdf

Generalitat de Catalunya. (2012). Pla de l'Energia i Canvi Climàtic a Catalunya 2012 - 2020. Barcelona. Available at: http://www20.gencat.cat/portal/ 
site/icaen/menuitem. $897 \mathrm{a} 4 \mathrm{be} 85 \mathrm{~d} 3 \mathrm{~b} 580 \mathrm{ec} 644968 \mathrm{bb0c0e1a0/?vgnextoid=}$ 4e2bad73a2ba6310VgnVCM1000008d0c1e0aRCRD\&vgnextchannel= 4e2bad73a2ba6310VgnVCM1000008d0cle0aRCRD\&newLang=ca_ES

IEA. (2011). Oil and Gas Security - Emergency Response of IEA Countries. Paris. Available at: http://www.iea.org/publications/freepublications/publication/ spain_2011.pdf

Jewell, J. (2011). The IEA Model of Short-term Energy Security (MOSES). Laxenburg: IEA.

Jewell, J., and Cherp, A. (2013). "Energy security assessment framework and three case studies," in International Handbook of Energy Security, eds H. Dyer and M. J. Trombetta (Cheltenham: Edward Elgar), 146-173.

MacKay, D. J. C. (2009). Sustainable Energy - Without the Hot Air. Cambridge: UIT.

Margalef, R. (1993). Teoría de los Sistemas Ecológicos. Barcelona: Publicacions de la Universitat de Barcelona.

Max-Neef, M. A., Elizalde, A., and Hopenhayn, M. (1991). Human Scale Development. Conception, Application and Further Reflections. New York: The Apex Press.

Newman, M. E. J. (2010). Networks: An Introduction. Oxford: Oxford University Press.

Odum, H. T. (2007). Environment, Power and Society for the Twenty-First Century. The Hierarchy of Energy. New York: Columbia University Press.

Odum, H. T., and Odum, E. C. (2001). A Prosperous Way Down: Principles and Policies. Boulder: University Press of Colorado.
Solé, R. V., Rosas-Casals, M., Corominas-Murtra, B., and Valverde, S. (2008). Robustness of the European power grids under intentional attack.Phys. Rev. E Stat. Nonlin. Soft Matter Phys. 77, 26102. doi:10.1103/PhysRevE.77.026102

Watts, D. J., and Strogatz, S. H. (1998). Collective dynamics of "small-world" networks. Nature 393, 440-442. doi:10.1038/30918

Conflict of Interest Statement: The authors declare that the research was conducted in the absence of any commercial or financial relationships that could be construed as a potential conflict of interest.

Received: 07 December 2013; accepted: 17 April 2014; published online: 12 May 2014. Citation: Rosas-Casals M, Marzo M and Salas-Prat P (2014) Sovereignty, robustness, and short-term energy security levels. The Catalonia case study. Front. Energy Res. 2:16. doi: 10.3389/fenrg.2014.00016

This article was submitted to Energy Systems and Policy, a section of the journal Frontiers in Energy Research.

Copyright (c) 2014 Rosas-Casals, Marzo and Salas-Prat. This is an open-access article distributed under the terms of the Creative Commons Attribution License (CC BY). The use, distribution or reproduction in other forums is permitted, provided the original author(s) orlicensor are credited and that the original publication in this journal is cited, in accordance with accepted academic practice. No use, distribution or reproduction is permitted which does not comply with these terms. 